\title{
Dietary supplementation with fish oil and safflower oil, during the finishing period, alters brisket muscle fatty acid profile and $n-6 / n-3$ ratio but not carcass traits of dairy beef bulls
}

\author{
C. J. Byrne, ${ }^{1,2} \odot$ S. Fair ${ }^{3}$ J. R. Dick, ${ }^{4}$ P. Lonergan, ${ }^{2}$ and D. A. Kenny ${ }^{1,2 *}$ \\ ${ }^{1}$ Animal and Bioscience Research Department, Teagasc Grange, Dunsany, Co. Meath, C15 PW93, Ireland; \\ ${ }^{2}$ School of Agriculture and Food Science, University College Dublin, Belfield, Dublin 4, D04 F6X4, Ireland; \\ ${ }^{3}$ Laboratory of Animal Reproduction, Department of Biological Sciences, University of Limerick, Limerick, V94 \\ T9PX, Ireland; and ${ }^{4}$ Institute of Aquaculture, School of Natural Sciences, University of Stirling, Stirling, Scotland, \\ FK9 4LA, UK
}

\section{ABSTRACT}

Objective: With increases in the global population, there is a need to identify strategies that increase beef output while maintaining or improving health benefits of beef products. Studies have demonstrated that there are many benefits to human health in response to reducing the dietary ratio of $n-6$ to n- 3 . The aim of this study was to characterize the carcass characteristics and brisket muscle fatty acid profile of young dairy-bred bulls following dietary supplementation with n-6 or n-3 PUFA.

Materials and Methods: Holstein-Friesian $(\mathrm{n}=43)$ and Jersey $(\mathrm{n}=7)$ bulls with a mean \pm SEM age and BW of $420.1 \pm 5.86 \mathrm{~d}$ and $382.0 \pm 8.94 \mathrm{~kg}$, respectively, were offered a cereal-based concentrate diet on an ad libitum basis, fortified with 1 of 3 lipid supplements: control (CTL; no supplementary lipid), n-6 PUFA safflower oil (SO), or n-3 PUFA enriched fish oil (FO). Bulls were individually offered their respective diet for 12 wk before slaughter. Carcass weight, conformation, and fat score were recorded at slaughter for all animals. Brisket muscle was collected from 26 randomly selected bulls, and lipid profile was analyzed using gas chromatography.

Results and Discussion: Total n-3 PUFA concentration was greater for FO than for either SO or CTL diets $(P<0.05)$. Although there was no difference in the muscle total n-6 concentration between $\operatorname{diets}(P=0.52)$, the ratio of n- 6 to n- 3 was 3.2 and 3.9 times lower for FO $(P$ $<0.001)$ than either CTL or SO diets, respectively. Total intake of n-3 PUFA accounted for $72 \%$ of the variation in

\footnotetext{
The authors declare no conflicts of interest[AU1: Are any of the authors current ARPAS members (i.e., should any author have the "PAS" designation after their name)? ].

${ }^{*}$ Corresponding author[AU2: Ensure all authors sign and return the copyright release form. ]: David.kenny@teagasc.ie
}

the ratio of n-6 to n-3. Despite the differences in fatty acid profiles, there was no effect of dietary lipid supplementation on carcass weight $(P=0.63)$, conformation $(P=$ $0.79)$, or fat score $(P=0.84)$.

Implications and Applications: Beef producers can feed diets enriched with n- 6 and n-3 PUFA, which would result in beef having potential health benefits and greater branding potential.

Key words: n-3, n-6, PUFA, lipids, nutraceutical

\section{INTRODUCTION}

It is widely accepted that PUFA are important for maintaining human health (Zárate et al., 2017), with medical professionals and dieticians recommending that SFA consumption be reduced and replaced with PUFA (Briggs et al., 2017). Although SFA make up a large portion of the fatty acid (FA) profile of beef, PUFA are also present, and there is potential to increase the n- 3 and n- 6 FA content through strategic dietary manipulation (Vahmani et al., 2015). However, to achieve an appreciable improvement in FA profile, supplemental dietary FA need to be protected from biohydrogenation in the rumen microbial ecosystem (Jenkins et al., 2008).

Consumers favor meat from animals that are reared on predominantly grass-based diets, with one reason being the enhanced conjugated linoleic acid (CLA; C18:2) content (Scollan et al., 2006; Daley et al., 2010). Although the SFA content is normally similar, irrespective of rearing diet, grass-based diets produce meat with a greater proportion of cholesterol-neutral SFA such as stearic acid and less total serum cholesterol-promoting FA such as myristic and palmitic acids (Daley et al., 2010).

In a review of the importance of the dietary ratio of $n-6$ to n-3 for human health, Simopoulos (2006) highlighted the fact that humans evolved consuming a diet with a 
ratio of n- 6 to n-3 of 1:1, whereas a modern western diet is now closer to $10: 1$ to $15: 1$, with consumption of red meat significantly contributing to this increase. It has been reported that the ratio of n- 6 to $\mathrm{n}-3$ in the longissimus thoracis, biceps femoris, and extensor carpi radialis was reduced when heifers were fed a diet supplemented with fish oil compared with sunflower oil at an inclusion rate of $6 \%$ of dietary DM (Wolf et al., 2018). In lambs, the use of safflower seeds as a dietary source of n- 6 FA resulted in greater ADG and a greater proportion of CLA in muscle compared with nonsupplemented controls (Kott et al., 2003). Additionally, feeding 3 or $6 \%$ safflower oil to lambs increased the proportion of linoleic acid in muscle compared with controls ( $0 \%$ safflower oil); however, the percentage of oil in the diet had no effect on growth and carcass characteristics of lambs (Boles et al., 2005).

Although the role of safflower supplementation in determining growth and carcass characteristics has been examined in lambs, less work has been carried out in cattle. Supplementation of safflower seeds, high in linoleic acid, has been reported to increase intestinal supply and postruminal disappearance of UFA compared with soybean and high-oleic-acid safflower, with the authors concluding that the availability of FA for metabolism is affected by fat source, indicating that the FA apparently available for metabolism are affected by dietary fat source (Scholljegerdes et al., 2004). Importantly, it has been noted that fish oil supplements are a more potent source of n-3 PUFA compared with plant-based n-3 supplements (Liu et al., 2018); Liu et al. demonstrated that plant-derived $\alpha$-linolenic acid is only one-eighth as potent as marine-based n-3 PUFA containing eicosapentaenoic acid (EPA) and docosahexaenoic acid (DHA), when reducing the risk of breast cancer.

Although fish oil may be considered more potent than plant-sourced PUFA, the need to increase dietary PUFA intake justifies testing of any potential source of dietary PUFA. Many epidemiological studies have reported that replacing SFA intake with PUFA intake reduces the risk of cardiovascular disease and diabetes as well as improves cognitive function and behavior (Briggs et al., 2017). These risks are further reduced when the proportion of PUFA intake that consists of n-3 PUFA increases (Lunn and Theobald, 2006). As such, including safflower oil as an alternative source of PUFA for ruminants warrants investigation.

Despite the increase in popularity of brisket beef (pectoralis profundus; Franklin and Mackay, 2015; Harris et al., 2017), there is a dearth of knowledge in the literature on the effects of PUFA supplementation on lipid profiles in brisket beef, carcass conformation, and fat score. Additionally, brisket muscle has a high level of i.m. fat (Troy et al., 2016), with a greater proportion of monounsaturated compared with saturated fat (Smith et al., 2012), making this cut a good candidate for further changing of the FA profile, which could promote health benefits. Therefore, we hypothesized that supplementation of dairy-bred bulls with rumen-protected n-6 or n-3 PUFA would beneficially alter brisket muscle FA profiles and improve carcass characteristics. The aim of this study was to characterize the brisket muscle FA profile following dietary supplementation with either n-6 or n-3 PUFA and to examine effects on commercially important carcass characteristics.

\section{MATERIALS AND METHODS}

All animal procedures were conducted under experimental license from the Irish Department of Health and Children. Protocols were in accordance with the Cruelty to Animals Act (Ireland 1876, as amended by European Communities regulations 2002 and 2005) and the European Community Directive 86/609/EC.

\section{Animal Management}

Animal management has been previously described (Byrne et al., 2017). Briefly, Holstein-Friesian (HF; n = 43) and Jersey $(\mathbf{J E} ; \mathrm{n}=7)$ bulls with a mean \pm SEM age and BW of $420.1 \pm 5.86 \mathrm{~d}$ and $382.0 \pm 8.94 \mathrm{~kg}$, respectively, were blocked based on breed, weight, and age and randomly assigned to 1 of 3 concentrate-based dietary treatments: (1) a nonsupplemented control (CTL, $\mathrm{n}=15),(2)$ rumen-protected safflower oil (SO, $\mathrm{n}=15)$, or (3) rumenprotected n-3 PUFA-enriched fish oil (Incromega; FO, n $=20$ ). Both fat supplements were supplied by Trouw Nutrition and included at $2 \%$ of the total diet. All diets were isonitrogenous and isocaloric. Feed composition has been reported previously by Byrne et al. (2017). Bulls were housed in a concrete slatted floor shed and individually fed using an electronic feeding system (Calan Inc.) for the initial 6 wk of the feeding period, followed by group feeding ( 5 bulls per treatment/pen) for the remaining $6 \mathrm{wk}$. Bulls were allowed $2 \mathrm{wk}$ to acclimatize to the individual feeding facility followed by $10 \mathrm{~d}$ acclimatization to their respective diets and were then offered diets ad libitum for $12 \mathrm{wk}$. All bulls received $5 \mathrm{~kg}$ (fresh weight) of grass silage daily. Bulls were slaughtered at a mean \pm SEM of $574.2 \pm$ $7.22 \mathrm{~d}$ of age, over a period of $4 \mathrm{~d}$.

At slaughter, carcass conformation grade and fat score were recorded using automatic methods as described by Allen (2007). On the same day as slaughter, brisket muscle samples were collected from $\mathrm{n}=26$ randomly selected bulls [CTL, $\mathrm{n}=8(\mathrm{HF}=6, \mathrm{JE}=2) ; \mathrm{SO}, \mathrm{n}=7(\mathrm{HF}=6$, $\mathrm{JE}=1) ; \mathrm{FO}, \mathrm{n}=11(\mathrm{HF}=10, \mathrm{JE}=1)]$, vacuum packed, and placed on ice for transportation before freezing at $-20^{\circ} \mathrm{C}$ until lipid analysis.

\section{Lipid Extraction and FA Analysis}

Total lipids were prepared according to the method of Folch et al. (1957), and nonlipid impurities were removed by washing with $0.88 \%$ (wt/vol) $\mathrm{KCl}$. The weight of lipids was determined gravimetrically after evaporation of solvent and overnight desiccation under vacuum. Fatty acid 
methyl esters (FAME) were prepared by acid-catalyzed transesterification of total lipids, $1 \%$ sulfuric acid in methanol, according to the method of Christie (2003). Isomerization of FA was checked, and this was confirmed by gas chromatography mass spectrometry. The extraction and purification of FAME was performed as described by Ghioni et al. (1996). The FAME were separated by GLC using a ThermoFisher Trace GC 2000 (ThermoFisher) equipped with a fused silica capillary column (ZBWax, 60 $\mathrm{m} \times 0.32 \times 0.25 \mathrm{~mm}$ i.d.; Phenomenex) with hydrogen as carrier gas and using on-column injection. The temperature gradient was from 50 to $150^{\circ} \mathrm{C}$ at $40^{\circ} \mathrm{C} / \mathrm{min}$ and then to $195^{\circ} \mathrm{C}$ at $1.5^{\circ} \mathrm{C} / \mathrm{min}$ and finally to $220^{\circ} \mathrm{C}$ at $2^{\circ} \mathrm{C} / \mathrm{min}$. Individual methyl esters were identified by comparison to known standards (Supelco 37-FAME mix; Sigma-Aldrich Ltd.) and by reference to published data (Ackman, 1980). Data were collected and processed using the Chromcard for Windows (version 2.00) computer package (Thermoquest Italia S.p.A.). Fatty acid content per gram of tissue was calculated using heptadecanoic acid (17:0) as internal standard, and FA data are reported as percentage of total FA. The limit of quantification was $0.06 \%$.

\section{Statistical Analysis}

All data were analyzed using statistical analysis software (SAS version 9.3, SAS Institute Inc.). Data were tested for normality (UNIVARIATE procedure) and, where appropriate, transformed to the power of lambda (TRANSREG procedure). Data were analyzed using ANOVA (MIXED procedure). The covariance matrix was determined for each variable by examining the Bayesian information criteria (smaller is better) value. Diet was inserted as a fixed effect, and breed and day of slaughter were inserted as random effects. Animal was the experimental unit. Data are reported as mean \pm SEM. Multiple regression analysis was used (REG and STEPWISE procedure) to identify statistically significant predictor variables for carcass weight. Multinomial logistic regression was used (LOGISTIC procedure), with a cumulative logit function, to identify significant predictors of fat score and carcass grade at slaughter. A $P<0.05$ was considered statistically significant.

\section{RESULTS AND DISCUSSION}

\section{Carcass Characteristics}

Average daily gain and individual animal DMI data have been reported previously (Byrne et al., 2017; Supplementary Table S1; https://doi.org/10.15232/aas.2021 -02158). There was no effect of diet on carcass weight, conformation, or fat score $(P=0.63$; Table 1$)$. Although altering the lipid profile of certain muscles in cattle may not lead to notable changes in the carcass characteristics of cattle, previous studies have reported that fishmealsupplemented cattle tended to be more feed efficient than control animals, highlighted by the reduced DMI on fishmeal but maintenance of a comparable ADG (Nicholson et al., 1992). In the current study, the lack of difference in DMI and ADG may account for the lack of alteration to carcass traits. Based on previous work from our own laboratory (Jordan et al., 2006), we hypothesized that PUFA, and particularly n-6 PUFA, supplementation would lead to an increase in feed conversion efficiency; however, this was not the case. Further work to explain why PUFA supplementation via rumen-protected supplements does not lead to more efficient production and thus better ADG and greater carcass weights and confirmation scores is warranted.

\section{FA Profile}

The effect of diet on FA profiles of muscle samples is presented as a proportion of total FA in Table 2 and as milligrams per $100 \mathrm{~g}$ of muscle in Table 3 . We observed no effect of diet on the percentage of total SFA and MUFA in muscle $(P>0.05)$. The FA profile of brisket muscle consists of predominantly SFA (40\%) and MUFA (50\%; Ekine-Dzivenu et al., 2014); similar concentrations were observed in our study. Palmitic and stearic acids were the main contributors to SFA concentrations at 25 and $10 \%$, respectively. We detected a greater concentration of iso margaric acid in bulls offered the CTL compared with the FO diet, indicating competition between FA for incorporation into the muscle $(P<0.05)$. Competition for incorporation into tissues has been reported in a range of

Table 1. Effects of dietary supplementation with safflower oil or fish oil on carcass characteristics in dairy-bred bulls

\begin{tabular}{lccccc} 
Item $^{1}$ & $\begin{array}{c}\text { Control } \\
(\mathbf{n}=\mathbf{1 5})\end{array}$ & $\begin{array}{c}\text { Safflower } \\
(\mathbf{n}-\mathbf{6} ; \mathbf{n}=\mathbf{1 5})\end{array}$ & $\begin{array}{c}\text { Fish oil } \\
(\mathbf{n}-\mathbf{3} ; \mathbf{n}=\mathbf{2 0})\end{array}$ & $\begin{array}{c}\text { Avg. } \\
\mathbf{S E M}\end{array}$ & $\boldsymbol{P}$-value \\
\hline Carcass weight $(\mathrm{kg})$ & 267.3 & 276.7 & 286.6 & 6.35 & 0.63 \\
Conformation score $\left(1-15^{2}\right)$ & 3.79 & 4.73 & 4.15 & 0.141 & 0.79 \\
Fat score $\left(1-15^{3}\right)$ & 6.71 & 6.73 & 6.70 & 0.184 & 0.84 \\
\hline
\end{tabular}

${ }^{1} E U$ scheme (EC 1208/1981) for conformation (E, U, R, O, P) and fat cover (1-5).

${ }^{2}$ Score: 1 = poorest confirmation (i.e., $\mathrm{P}-$ ), 15 = best confirmation (i.e., $\mathrm{E}+$ ).

${ }^{3}$ Score: 1 = lowest fatness (i.e., $\left.1-\right), 15=$ highest fatness (i.e., $5+$ ). 
muscle types (Wolf et al., 2018). These authors reported that when heifers are supplemented with FA, n-3 and n-6 PUFA will compete for the same enzymes, meaning that their incorporation will differ between muscle types; had that been the case in the current study, we would have expected that SFA would have decreased in bulls offered the FO and SO diets, particularly as these oils were offered in a rumen-protected form.

We observed that adrenic acid was greater in CTL bulls than FO $(P<0.05)$, with SO intermediate. There are few published studies reporting differences in adrenic acid as a result of dietary supplementation, although adrenic acid concentrations are not reported at all in most cases. The reduction in adrenic acid on the FO diet in this study agrees with the previous report in Charolais steers (Scollan et al., 2001) where adrenic acid concentration decreased as the amount of FO in the diet increased.

The total n-6 PUFA in muscle was unaffected by diet $(P=0.52)$. Eicosapentaenoic acid was greater in brisket muscle of bulls on FO than either CTL or SO diets ( $P$ $<0.001)$. Total MUFA concentration was unaffected by diet, in agreement with previous findings from our group (Conte et al., 2019). This is likely a result of the lack of difference in observed concentrations of palmitoleic acid (n-7; $P=0.47)$ and oleic acid $(P=0.56)$, both large contributors to total MUFA concentration. In line with the findings of the current study, it has been reported that palmitoleic acid (n-7) and oleic acid make up the greatest proportion of MUFA in brisket adipose tissue (Shah et al., 2006). However, in contrast to our study, where there was no effect of diet; offering a diet containing $15 \%$ sunflower seeds resulted in increased proportions of palmitoleic acid (n-7) and oleic acid compared with a control diet. Additionally, palmitoleic acid (n-9) was greater in CTL compared with FO, with SO having an intermediate concentration; this was unaffected in the study by Shah et al. (2006). These results suggest that MUFA are altered by dietary supplementation with $\mathrm{FO}$ but $\mathrm{SO}$ has minimal effect on the concentrations of MUFA. The increase in vaccenic acid in response to dietary supplementation of sunflower oil has been reported in Charolais, Simmental, and Jersey steers (Mir et al., 2003); however, the effects of FO supplementation were not reported in their review. Vaccenic acid is a well-known precursor to CLA following conversion by $\Delta^{9}$-desaturase in ruminant tissues (Fernie, 2003). Notwithstanding this, despite greater vaccenic acid in the FO compared with CTL bulls $(P<0.05)$, there were no differences in CLA between diets in the current study $(P=0.73)$. Previous work from our research group has demonstrated that $\Delta^{9}$-desaturase is downregulated when bulls are fed a diet containing $2 \%$ FO, potentially explaining why vaccenic acid was not converted to CLA (Waters et al., 2009). The proportions of total n-6 PUFA, in muscle, did not differ between diets, and within the n-6 group $(P=0.52)$, only adrenic acid was greater in CTL compared with FO-fed bulls, with the SO-fed bulls not differing from either. Despite the fact that the SO diet in this study contained $\sim 12$ and $\sim 33 \%$ more linoleic acid than the CTL and FO diets, respectively, there was no difference in linoleic acid concentration in muscle $(P$ $=0.38)$. Consistent with this observation, we have previously reported, for the same animals, a lack of difference in linoleic acid concentration in sperm cells (Byrne et al., 2017) and hypothesized that linoleic acid may have undergone elongation to form docosapentaenoic (DPA n-6). However, the muscle lipid data reported here indicate that this was likely not the case. In fact, DPA n- 6 was below detectable concentrations for animals on both the CTL and SO diets and at a low concentration in bulls on the FO diet. It is possible that DPA n- 6 was converted to arachidonic acid, as was reported for human cell lines (Tian et al., 2016), or, perhaps more likely, that DPA n-6 was too low in the diet offered (Byrne et al., 2017), resulting in minimal incorporation into brisket muscle.

Docosapentaenoic (DPA n-3) and docosahexaenoic acid were both greater in bulls fed FO compared with CTL $(P<0.05)$, with those fed SO similar to both CTL and FO-fed bulls. As a result, total n-3 content of muscle was greater in bulls fed FO than bulls fed either CTL or SO $\operatorname{diets}(P<0.001)$. The proportions of EPA, DPA n-3, and DHA in muscle of bulls on the FO diet were double those of bulls on either the CTL or SO diets. This resulted in the total n-3 proportion on the $\mathrm{FO}$ diet being 3 times greater than either the CTL or SO diets. Large increases in these $3 \mathrm{FA}$ as a result of dietary PUFA n-3 supplementation have been previously identified by our group (Childs et al., 2008; Dunne et al., 2011) and others (Dannenberger et al., 2013). Additionally, Dannenberger et al. (2013) extensively reviewed methods of improving beef attributes such as health benefits and eating quality, with dietary supplementation of rumen-protected lipids highlighted as one of the most effective approaches for altering lipid profiles in animal tissues. Successfully increasing the quantity of long-chain FA allows for production of red meat that can be promoted as having health benefits, particularly in terms of cardiac disease and diabetes (Mozaffarian et al., 2010). Indeed, it has been demonstrated that ground beef produced from brisket has unique FA and functional characteristics, with the conclusion that these beef cuts could be used to produce beef products with distinctive compositional and flavor attributes. Furthermore, the differences in FA composition may be sufficient to elicit different responses in risk factors associated cardiovascular disease (Blackmon et al., 2015).

While diet did not affect the total PUFA content in muscle $(P>0.50)$, bulls offered FO had a ratio of n-6 to n-3 that was 3.2 and 3.9 times lower than their contemporaries offered CTL and SO diets, respectively $(P<0.001)$. The total intake of n-3 PUFA (grams) accounted for $72 \%$ of the variation in the ratio of n-6 to n-3 ( $y=6.241-0.104 x$; $\mathrm{R}^{2}=0.72, P<0.001$ ), whereas MUFA intake (grams) accounted for an additional $4 \%$ of the variation in the ratio of n-6 to $\mathrm{n}-3\left(y=6.24+0.09 x ; \mathrm{R}^{2}=0.04, P=0.05\right)$. Two previous studies have reported the natural average ratio 
Table 2. Mean fatty acid (\%) concentration in brisket muscle (pectoralis profundus) from dairybred bulls offered for 12 wk before slaughter a control diet (CTL) or diet supplemented with safflower oil (SO) or fish oil (FO) 1

\begin{tabular}{|c|c|c|c|c|c|}
\hline Item & CTL & so & FO & $\begin{array}{l}\text { Avg. } \\
\text { SEM }\end{array}$ & $P$-value \\
\hline Lipid content & 5.84 & 5.44 & 4.53 & 0.721 & 0.70 \\
\hline Myristic (C14:0) & 2.41 & 2.30 & 2.32 & 0.079 & 0.95 \\
\hline Pentadecylic (C15:0) & 0.33 & 0.31 & 0.30 & 0.011 & 0.12 \\
\hline Palmitic $(16: 0)$ & 25.04 & 23.91 & 25.43 & 0.411 & 0.27 \\
\hline Anteiso margaric (C17:0) & 0.37 & 0.33 & 0.34 & 0.009 & 0.13 \\
\hline Iso margaric $(\mathrm{C} 17: 0)$ & $0.68^{a}$ & $0.61^{\mathrm{ab}}$ & $0.54^{\mathrm{b}}$ & 0.021 & $<0.05$ \\
\hline Stearic $(18: 0)$ & 10.56 & 10.66 & 10.92 & 0.289 & 0.96 \\
\hline Arachidic $(\mathrm{C} 20: 0)$ & 0.09 & 0.08 & 0.09 & 0.004 & 0.71 \\
\hline Behenic (C22:0) & ND & ND & 0.09 & 0.015 & - \\
\hline Lignoceric (C24:0) & 0.08 & ND & 0.07 & 0.004 & $0.57^{2}$ \\
\hline Total saturated & 39.50 & 38.22 & 40.00 & 0.553 & 0.38 \\
\hline Myristoleic (C14:1n-5) & 0.87 & 0.89 & 0.71 & 0.066 & 0.76 \\
\hline Palmitoleic (C16:1n-9) & $0.12^{\mathrm{a}}$ & $0.11^{\mathrm{ab}}$ & $0.09^{b}$ & 0.006 & $<0.05$ \\
\hline Palmitoleic (C16:1n-7) & 5.10 & 4.93 & 4.36 & 0.217 & 0.47 \\
\hline Palmitoleic (C16:1) & 0.35 & 0.34 & 0.30 & 0.017 & 0.70 \\
\hline Civetic (C17:1) & 1.04 & 0.97 & 0.95 & 0.031 & 0.16 \\
\hline Oleic (C18:1n-9) & 40.03 & 38.66 & 37.25 & 0.909 & 0.56 \\
\hline Asleptic (C18:1n-7) & $3.61^{a}$ & $4.35^{\mathrm{ab}}$ & $4.34^{\mathrm{b}}$ & 0.128 & $<0.05$ \\
\hline Vaccenic $(18: 1)$ & $0.23^{\mathrm{a}}$ & $0.35^{\mathrm{ab}}$ & $0.43^{b}$ & 0.031 & $<0.05$ \\
\hline Gadoleic $(20: 1 n-11)$ & 0.14 & 0.17 & 0.15 & 0.009 & 0.88 \\
\hline Gondoic (C20:1n-9) & 0.41 & 0.33 & 0.37 & 0.022 & 0.54 \\
\hline Cetoleic $(22: 1 n-11)$ & 0.15 & ND & 0.11 & 0.036 & $0.89^{2}$ \\
\hline Erucic (C22:1n-9) & ND & ND & ND & & - \\
\hline Nervonic (C24:1n-9) & 0.09 & ND & 0.08 & 0.006 & $0.69^{2}$ \\
\hline Total monounsaturated & 52.06 & 51.13 & 48.96 & 1.096 & 0.61 \\
\hline Linoleic (C18:2n-6) & 4.36 & 5.98 & 4.82 & 0.509 & 0.38 \\
\hline Gamma-linolenic (C18:3n-6) & 0.11 & 0.08 & 0.08 & 0.010 & 0.16 \\
\hline Conjugated linoleic acid & 0.28 & 0.36 & 0.30 & 0.021 & 0.73 \\
\hline Eicosadienoic $(20: 2 n-6)$ & 0.10 & 0.13 & 0.15 & 0.010 & 0.17 \\
\hline Dihomo-gamma-linolenic (C20:3n-6) & 0.23 & 0.28 & 0.23 & 0.035 & 0.92 \\
\hline Arachidonic (C20:4n-6) & 1.07 & 1.09 & 0.84 & 0.155 & 0.80 \\
\hline Adrenic (C22:4n-6) & $0.17^{a}$ & $0.12^{\mathrm{ab}}$ & $0.07^{\mathrm{b}}$ & 0.021 & $<0.05$ \\
\hline Docosapentaenoic (C22:5n-6) & ND & ND & 0.13 & 0.150 & - \\
\hline Total n-6 & 6.28 & 7.97 & 6.41 & 0.711 & 0.52 \\
\hline Alpha-linolenic (C18:3n-3) & 0.33 & 0.31 & 0.40 & 0.020 & 0.16 \\
\hline Stearidonic $(18: 4 n-3)$ & 0.11 & 0.08 & 0.13 & 0.026 & 0.78 \\
\hline Eicosatrienoic $(20: 3 n-3)$ & ND & ND & 0.09 & 0.004 & - \\
\hline Eicosatetraenoic $(20: 4 n-3)$ & ND & ND & 0.28 & 0.039 & - \\
\hline Eicosapentaenoic (20:5n-3) & $0.23^{\mathrm{a}}$ & $0.22^{\mathrm{a}}$ & $1.21^{\mathrm{b}}$ & 0.173 & $<0.001$ \\
\hline Heneicosapentaenoic $(21: 5 n-3)$ & ND & ND & ND & & - \\
\hline Docosapentaenoic (C22:5n-3) & $0.42^{\mathrm{a}}$ & $0.44^{\mathrm{ab}}$ & $0.92^{b}$ & 0.095 & $<0.05$ \\
\hline Docosahexaenoic (C22:6n-3) & $0.13^{a}$ & $0.19^{a b}$ & $0.45^{b}$ & 0.062 & $<0.05$ \\
\hline Total n-3 & $1.04^{\mathrm{a}}$ & $1.10^{\mathrm{a}}$ & $3.37^{\mathrm{b}}$ & 0.348 & $<0.001$ \\
\hline Total PUFA & 7.32 & 9.07 & 9.77 & 0.943 & 0.50 \\
\hline Ratio of total $n-6$ to total $n-3$ & $6.72^{\mathrm{a}}$ & $8.17^{\mathrm{a}}$ & $2.09^{\mathrm{b}}$ & 0.021 & $<0.001$ \\
\hline
\end{tabular}

a,b Values with different superscripts within row differ at $P<0.05$.

${ }^{1}$ Limit of quantification $=0.06 \%$; ND $=$ not detectable.

${ }^{2}$ Only CTL and FO compared.

of n-6 to n-3 in brisket adipose as 2.65 (He et al., 2011) or 7.99 (Ekine-Dzivenu et al., 2014). The FO diet (n-6:n-3 $=2.09$ ) in our study resulted in a muscle that had a ratio of $\mathrm{n}-6$ to $\mathrm{n}-3 \sim 3$ times lower than muscle from animals offered either the CTL (n-6:n-3 =6.72) or SO (n-6:n-3 $=8.17)$ diets. This represents a large advantage in terms 
Table 3. Mean fatty acid content $(\mathrm{mg} / 100 \mathrm{~g})$ in brisket muscle (pectoralis profundus) from dairy-bred bulls offered for $12 \mathrm{wk}$ before slaughter a control diet (CTL) or diet supplemented with safflower oil (SO) or fish oil (FO)

\begin{tabular}{|c|c|c|c|c|c|}
\hline Item & CTL & so & FO & $\begin{array}{l}\text { Avg. } \\
\text { SEM }\end{array}$ & $P$-value \\
\hline Myristic (C14:0) & 116.84 & 101.28 & 80.54 & 14.792 & 0.80 \\
\hline Pentadecylic (C15:0) & 15.48 & 12.99 & 10.38 & 1.999 & 0.54 \\
\hline Palmitic (16:0) & $1,146.02$ & $1,020.60$ & 853.15 & 141.248 & 0.80 \\
\hline Anteiso margaric (C17:0) & 17.29 & 14.42 & 11.24 & 2.119 & 0.66 \\
\hline Iso margaric $(\mathrm{C} 17: 0)$ & 31.34 & 26.49 & 18.13 & 3.917 & 0.38 \\
\hline Stearic $(18: 0)$ & 451.73 & 432.52 & 333.95 & 52.154 & 0.64 \\
\hline Arachidic (C20:0) & 3.04 & 3.13 & 2.86 & 0.435 & 0.87 \\
\hline Behenic (C22:0) & $\mathrm{ND}^{1}$ & ND & 6.31 & 3.745 & - \\
\hline Lignoceric (C24:0) & 0.96 & 0.93 & 2.87 & 1.163 & 0.80 \\
\hline Total saturated & $1,781.80$ & $1,611.22$ & $1,312.44$ & 215.484 & 0.66 \\
\hline Myristoleic (C14:1n-5) & 46.57 & 41.85 & 26.98 & 6.879 & 0.69 \\
\hline Palmitoleic (C16:1n-9) & 5.38 & 5.21 & 3.01 & 0.685 & 0.29 \\
\hline Palmitoleic (C16:1n-7) & 244.43 & 226.29 & 157.41 & 33.424 & 0.62 \\
\hline Palmitoleic (C16:1) & 16.38 & 14.50 & 10.31 & 2.212 & 0.50 \\
\hline Civetic (C17:1) & 47.60 & 41.45 & 32.63 & 6.542 & 0.52 \\
\hline Oleic (C18:1n-9) & $1,867.38$ & $1,694.90$ & $1,337.32$ & 249.609 & 0.66 \\
\hline Asleptic (C18:1n-7) & 163.60 & 184.04 & 146.19 & 24.733 & 0.74 \\
\hline Vaccenic $(18: 1)$ & 8.50 & 16.15 & 11.20 & 1.836 & 0.36 \\
\hline Gadoleic (20:1n-11) & 6.53 & 7.77 & 5.91 & 1.066 & 0.72 \\
\hline Gondoic (C20:1n-9) & 17.85 & 14.43 & 13.78 & 2.534 & 0.70 \\
\hline Paullinic $(20: 1 n-7)$ & ND & ND & ND & ND & - \\
\hline Cetoleic (22:1n-11) & 5.31 & 2.46 & 2.84 & 1.386 & 0.46 \\
\hline Erucic (C22:1n-9 cis) & ND & ND & ND & ND & - \\
\hline Nervonic (C24:1n-9) & 1.64 & 3.67 & 0.97 & 0.622 & 0.51 \\
\hline Total monounsaturated & $2,382.38$ & $2,206.15$ & $1,717.50$ & 319.937 & 0.67 \\
\hline Linoleic (C18:2n-6) & $146.82^{\mathrm{ab}}$ & $192.57^{a}$ & $115.24^{b}$ & 12.815 & $<0.05$ \\
\hline Gamma-linolenic (C18:3n-6) & 3.56 & 2.97 & 3.24 & 0.699 & 0.97 \\
\hline Conjugated linoleic acid & 12.48 & 17.84 & 9.67 & 2.222 & 0.78 \\
\hline Eicosadienoic $(20: 2 n-6)$ & 3.60 & 4.37 & 3.13 & 0.291 & 0.29 \\
\hline Dihomo-gamma-linolenic (C20:3n-6) & $6.48^{\mathrm{a}}$ & $7.32^{\mathrm{a}}$ & $4.43^{\mathrm{b}}$ & 0.360 & $<0.001$ \\
\hline Arachidonic (C20:4n-6) & $27.21^{\mathrm{a}}$ & $27.66^{\mathrm{a}}$ & $16.73^{b}$ & 1.343 & $<0.001$ \\
\hline Adrenic (C22:4n-6) & $3.35^{\mathrm{a}}$ & $3.05^{\mathrm{a}}$ & $0.83^{\mathrm{b}}$ & 0.332 & $<0.001$ \\
\hline Docosapentaenoic (C22:5n-6) & 12.49 & ND & 1.61 & 2.721 & - \\
\hline Total n-6 & $201.58^{\mathrm{ab}}$ & $253.21^{\mathrm{a}}$ & $151.03^{b}$ & 15.699 & $<0.05$ \\
\hline Alpha-linolenic (C18:3n-3) & 13.29 & 11.96 & 11.05 & 1.447 & 0.87 \\
\hline Stearidonic $(18: 4 n-3)$ & 2.93 & 1.54 & 2.65 & 0.625 & 0.50 \\
\hline Eicosatrienoic (20:3n-3) & ND & ND & 1.78 & 0.329 & - \\
\hline Eicosatetraenoic $(20: 4 n-3)$ & ND & ND & 6.50 & 0.891 & - \\
\hline Eicosapenteanoic $(20: 5 n-3)$ & $3.96^{\mathrm{a}}$ & $4.9^{\mathrm{a}}$ & $22.49^{b}$ & 2.156 & $<0.001$ \\
\hline Heneicosapenteanoic $(21: 5 n-3)$ & ND & ND & ND & ND & - \\
\hline Docosapentaenoic (C22:5n-3) & $10.62^{a}$ & $11.77^{\mathrm{a}}$ & $19.53^{b}$ & 1.038 & $<0.001$ \\
\hline Docosahexaenoic (C22:6n-3) & $2.16^{\mathrm{a}}$ & $3.52^{\mathrm{a}}$ & $11.03^{b}$ & 1.846 & $<0.001$ \\
\hline Total n-3 & $29.40^{a}$ & $30.97^{a}$ & $72.78^{\mathrm{b}}$ & 5.038 & $<0.001$ \\
\hline Total PUFA & 230.98 & 284.18 & 223.80 & 15.994 & 0.28 \\
\hline 16:0 DMA & 14.01 & 20.02 & 15.94 & 2.163 & 0.38 \\
\hline 18:0 DMA & 12.05 & 15.58 & 15.90 & 1.577 & 0.35 \\
\hline 18:1 DMA & 8.42 & 7.10 & 6.92 & 0.545 & 0.79 \\
\hline Total DMA & 25.46 & 40.33 & 31.15 & 4.612 & 0.29 \\
\hline Total & $4,414.25$ & $4,136.12$ & $3,279.23$ & 547.060 & - \\
\hline
\end{tabular}

a,b Values with different superscripts within row differ at $P<0.05$.

${ }^{1} \mathrm{ND}=$ not detectable[AU3: Please define DMA.].

*Only CTL and FO compared[AU4: No asterisks in table. Okay to delete footnote?]. 
of the health benefits to humans when beef is included in their diet (Simopoulos, 2016). The importance of n-3 PUFA in the cattle diet, in terms of reducing the ratio of $n-6$ to $n-3$, is further evidenced by the finding that a 1-g increase in $\mathrm{n}-3$ PUFA intake results in $0.1 \%$ reduction in this important ratio. In addition to a reduced ratio of n-6 to n-3, a 100-g serving of beef from the current study would provide $13 \%$ of the recommended daily intake of $500 \mathrm{mg}$ of EPA and DHA according to recommendations of Vannice and Rasmussen (2014). The high level of i.m. fat in brisket muscle (Troy et al., 2016) may no longer be perceived as an unhealthy aspect of this cut if the proportions of healthier lipids can be increased.

The correlation coefficients between FA intakes, n-3, $\mathrm{n}-6$, and total PUFA concentrations in muscle, as well as carcass weight, are presented in Table 4 . We detected significant positive associations, with an $\mathrm{r}$-value greater than 0.75, between MUFA and SFA intake, n-3 and MUFA intake, total PUFA intake and both SFA and MUFA intakes, $\mathrm{n}-3$ concentration (\%) in muscle and n-3 intake, and also $n-6$ concentration (n-6) in muscle and total PUFA in muscle. There was a significant negative relationship between n-3 intake and the ratio of n- 6 to n- 3 in muscle ( $\mathrm{r}=$ $-0.85 ; P<0.001)$. Wood and Enser $(2017)$ have recently reviewed the importance of manipulating the FA composition of beef so that nutritional value and meat quality can be maintained. This relationship detected in our study further highlights the importance of maximizing the intake of n-3 PUFA or their precursors in the ruminant diet. Of the various FA groupings examined, the total intake of SFA accounted for $17 \%$ of the variation in carcass weight $(y=$ $\left.192.75+1.81 x ; \mathrm{R}^{2}=0.17, P<0.05\right)$. As SFA make up to 68 to $80 \%$ of total $\mathrm{FA}$, it is possible that the association between SFA intake and carcass weight is due to a relationship between DMI and carcass weight; further work on this is necessary because could help optimize the level of SFA supplementation required to positively influence carcass traits with the level of PUFA required to improve beef nutritional quality.

These results highlight that the lipid profile of brisket muscle can be altered using dietary supplementation to increase the concentrations of desirable long-chain FA. As brisket muscle is known for its high level of i.m. fat, dietary regimens leading to improvements in the composition of this fat would facilitate the promotion of brisket beef as a healthier product than has been possible to date.

\section{APPLICATIONS}

By increasing the amount of long-chain PUFA in beef, via the animal's diet, beef producers can promote a product that is more beneficial to human health. Although this increase in long-chain PUFA does not increase carcass weights, the economic benefit for the producer will be an increased demand for a healthier beef product that may contribute to a reduction in the incidence of heart disease,

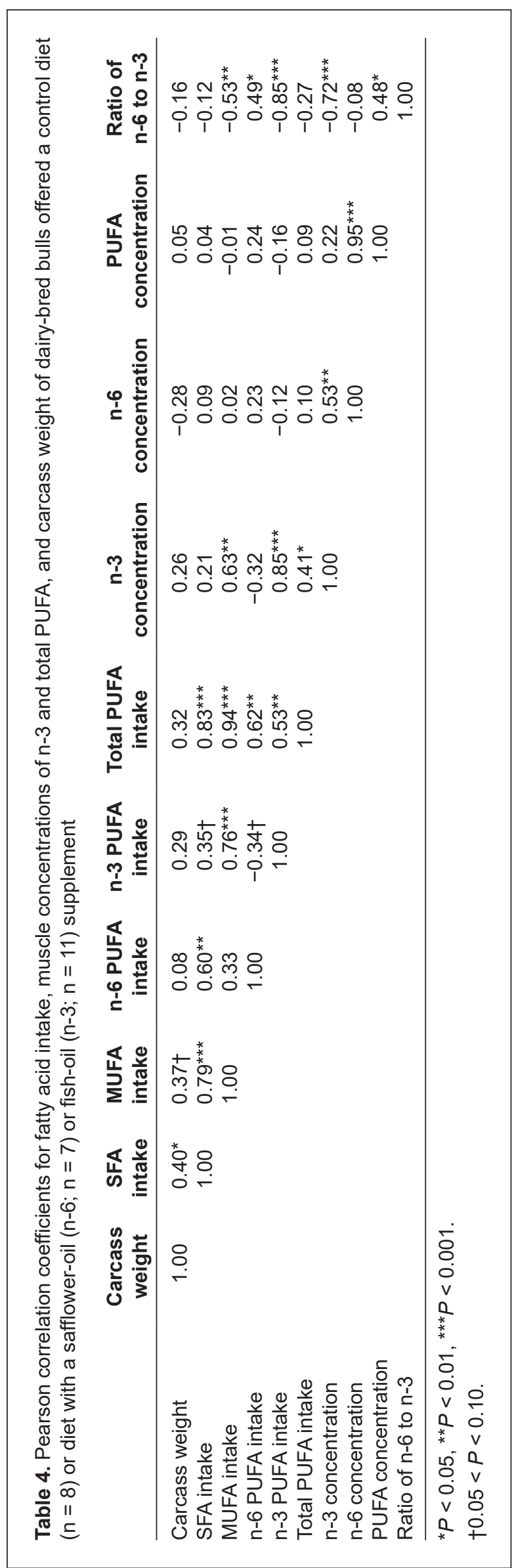


diabetes, and other conditions associated with high-fat diets containing excess SFA.

\section{ACKNOWLEDGMENTS}

We gratefully acknowledge support from the Department of Agriculture, Food and the Marine, Kildare Street, Dublin, Ireland, under the Research Stimulus Fund (Project $11 / \mathrm{S} / 116)$.

\section{LITERATURE CITED}

Ackman, R. 1980. Fish lipids, Part 1. Pages 86-103 in Advances in Fish Science and Technology. J. J. Connell, Torry Res. Stn., ed. Fishing News Books Ltd.

Allen, P. 2007. New methods for grading beef and sheep carcasses. Pages 39-47 in Evaluation of Carcass and Meat Quality in Cattle and Sheep. C. Lazzaroni, S. Gigli, and D. Gabiña, ed. Vol. 123. Wageningen Acad. Publ. https://doi.org/10.3920/978-90-8686-610-6.

Blackmon, T., R. K. Miller, C. Kerth, and S. B. Smith. 2015. Ground beef patties prepared from brisket, flank and plate have unique fatty acid and sensory characteristics. Meat Sci. 103:46-53. https://doi .org/10.1016/j.meatsci.2015.01.004

Boles, J. A., R. W. Kott, P. G. Hatfield, J. W. Bergman, and C. R. Flynn. 2005. Supplemental safflower oil affects the fatty acid profile, including conjugated linoleic acid, of lamb. J. Anim. Sci. 83:21752181. https://doi.org/10.2527/2005.8392175x.

Briggs, M. A., K. S. Petersen, and P. M. Kris-Etherton. 2017. Saturated fatty acids and cardiovascular disease: Replacements for saturated fat to reduce cardiovascular risk. Healthcare (Basel, Switzerland) 5:29. https://doi.org/10.3390/healthcare5020029.

Byrne, C. J., S. Fair, A. M. English, S. A. Holden, J. R. Dick, P. Lonergan, and D. A. Kenny. 2017. Dietary polyunsaturated fatty acid supplementation of young post-pubertal dairy bulls alters the fatty acid composition of seminal plasma and spermatozoa but has no effect on semen volume or sperm quality. Theriogenology 90:289-300. https: //doi.org/10.1016/j.theriogenology.2016.12.014.

Childs, S., A. A. Hennessy, J. M. Sreenan, D. C. Wathes, Z. Cheng, C. Stanton, M. G. Diskin, and D. A. Kenny. 2008. Effect of level of dietary n-3 polyunsaturated fatty acid supplementation on systemic and tissue fatty acid concentrations and on selected reproductive variables in cattle. Theriogenology 70:595-611. https://doi.org/10.1016/j .theriogenology.2008.04.002.

Christie, W. W. 2003. 13-Phenyltridec-9-enoic and 15-phenylpentadec-9-enoic acids in Arum maculatum seed oil. Eur. J. Lipid Sci. Technol. 105:779-780. https://doi.org/10.1002/ejlt.200300865.

Conte, G., A. Serra, L. Casarosa, F. Ciucci, A. Cappucci, E. Bulleri, L. Corrales-Retana, A. Buccioni, and M. Mele. 2019. Effect of linseed supplementation on total longissimus muscle lipid composition and shelf-life of beef from young Maremmana bulls. Front. Vet. Sci. 5:326. https://doi.org/10.3389/fvets.2018.00326.

Daley, C. A., A. Abbott, P. S. Doyle, G. A. Nader, and S. Larson. 2010. A review of fatty acid profiles and antioxidant content in grassfed and grain-fed beef. Nutr. J. 9:10. https://doi.org/10.1186/1475 $-2891-9-10$

Dannenberger, D., K. Nuernberg, A. Herdmann, G. Nuernberg, E. Hagemann, and W. Kienast. 2013. Dietary PUFA intervention affects fatty acid- and micronutrient profiles of beef and related beef products. Foods 2:295-309. https://doi.org/10.3390/foods2030295.

Dunne, P. G., J. Rogalski, S. Childs, F. J. Monahan, D. A. Kenny, and A. P. Moloney. 2011. Long chain n-3 polyunsaturated fatty acid concentration and color and lipid stability of muscle from heifers of- fered a ruminally protected fish oil supplement. J. Agric. Food Chem. 59:5015-5025. https://doi.org/10.1021/jf200232e.

Ekine-Dzivenu, C., L. Chen, M. Vinsky, N. Aldai, M. E. Dugan, T. A. McAllister, Z. Wang, E. Okine, and C. Li. 2014. Estimates of genetic parameters for fatty acids in brisket adipose tissue of Canadian commercial crossbred beef steers. Meat Sci. 96:1517-1526. https://doi .org/10.1016/j.meatsci.2013.10.011.

Fernie, C. E. 2003. Conjugated linoleic acid. Pages 1581-1587 in Encyclopedia of Food Sciences and Nutrition. 2nd ed. B. Caballero, ed. Acad. Press. https://doi.org/10.1016/B0-12-227055-X/01394-8.

Folch, J., M. Lees, and G. H. S. Stanley. 1957. A simple method for the isolation and purification of total lipids from animal tissues. J. Biol. Chem. 226:497-509. https://doi.org/10.1016/S0021-9258(18)64849-5.

Franklin, A., and J. Mackay. 2015. Franklin Barbecue: A Meat-Smoking Manifesto. Ten Speed Press.

Ghioni, C., J. G. Bell, and J. R. Sargent. 1996. Polyunsaturated fatty acids in neutral lipids and phospholipids of some freshwater insects. Comp. Biochem. Physiol. B Biochem. Mol. Biol. 114:161-170. https:/ /doi.org/10.1016/0305-0491(96)00019-3.

Harris, M. K., R. R. Riley, A. N. Arnold, R. K. Miller, D. B. Griffin, K. B. Gehring, and J. W. Savell. 2017. Assessment of postmortem aging effects on Texas-style barbecue beef briskets. Meat Muscle Biol. 1:46-52. https://doi.org/10.22175/mmb2017.01.0003.

He, M. L., P. S. Mir, R. Sharma, K. A. Schwartzkopf-Genswein, T. Entz, G. Travis, M. E. R. Dugan, D. Rolland, E. K. Okine, and M. V. Dodson. 2011. Effect of supplementation of beef steer diets with oil containing $\mathrm{n} 6$ and $\mathrm{n} 3$ fatty acids and $48 \mathrm{~h}$ feed withdrawal treatments on animal productivity, carcass characteristics and fatty acid composition. Livest. Sci. 142:253-263. https://doi.org/10.1016/j.livsci .2011.08.002

Jenkins, T., R. Wallace, P. Moate, and E. Mosley. 2008. Board-invited review: Recent advances in biohydrogenation of unsaturated fatty acids within the rumen microbial ecosystem. J. Anim. Sci. 86:397-412. https://doi.org/10.2527/jas.2007-0588.

Jordan, E., D. Kenny, M. Hawkins, R. Malone, D. Lovett, and F. O'mara. 2006. Effect of refined soy oil or whole soybeans on intake, methane output, and performance of young bulls. J. Anim. Sci. 84:2418-2425. https://doi.org/10.2527/jas.2005-354.

Kott, R. W., P. G. Hatfield, J. W. Bergman, C. R. Flynn, H. Van Wagoner, and J. A. Boles. 2003. Feedlot performance, carcass composition, and muscle and fat CLA concentrations of lambs fed diets supplemented with safflower seeds. Small Rumin. Res. 49:11-17. https:// doi.org/10.1016/S0921-4488(03)00052-X.

Liu, J., S. A. Abdelmagid, C. J. Pinelli, J. M. Monk, D. M. Liddle, L. M. Hillyer, B. Hucik, A. Silva, S. Subedi, G. A. Wood, L. E. Robinson, W. J. Muller, and D. W. L. Ma. 2018. Marine fish oil is more potent than plant-based n-3 polyunsaturated fatty acids in the prevention of mammary tumors. J. Nutr. Biochem. 55:41-52. https://doi.org/10 .1016/j.jnutbio.2017.12.011.

Lunn, J., and H. E. Theobald. 2006. The health effects of dietary unsaturated fatty acids. Nutr. Bull. 31:178-224. https://doi.org/10 $.1111 / \mathrm{j} .1467-3010.2006 .00571 . x$

Mir, P., M. Ivan, M. He, B. Pink, E. Okine, L. Goonewardene, T. McAllister, R. Weselake, and Z. Mir. 2003. Dietary manipulation to increase conjugated linoleic acids and other desirable fatty acids in beef: A review. Can. J. Anim. Sci. 83:673-685. https://doi.org/10 .4141/A03-002.

Mozaffarian, D., R. Micha, and S. Wallace. 2010. Effects on coronary heart disease of increasing polyunsaturated fat in place of saturated fat: A systematic review and meta-analysis of randomized controlled trials. PLoS Med. 7:e1000252-e1000252. https://doi.org/10.1371/ journal.pmed.1000252. 
Nicholson, J. W. G., E. Charmley, and R. S. Bush. 1992. The effect of supplemental protein source on ammonia levels in rumen fluid and blood and intake of alfalfa silage by beef cattle. Can. J. Anim. Sci. 72:853-862. https://doi.org/10.4141/cjas92-097.

Scholljegerdes, E. J., B. W. Hess, G. E. Moss, D. L. Hixon, and D. C. Rule. 2004. Influence of supplemental cracked high-linoleate or higholeate safflower seeds on site and extent of digestion in beef cattle. J. Anim. Sci. 82:3577-3588. https://doi.org/10.2527/2004.82123577x.

Scollan, N., J.-F. Hocquette, K. Nuernberg, D. Dannenberger, I. Richardson, and A. Moloney. 2006. Innovations in beef production systems that enhance the nutritional and health value of beef lipids and their relationship with meat quality. Meat Sci. 74:17-33. https://doi.org/10 .1016/j.meatsci.2006.05.002.

Scollan, N. D., N. J. Choi, E. Kurt, A. V. Fisher, M. Enser, and J. D. Wood., 2001. Manipulating the fatty acid composition of muscle and adipose tissue in beef cattle. Br. J. Nutr. 85:115-124.

Shah, M. A., P. S. Mir, J. L. Aalhus, J. Basarab, and E. K. Okine. 2006. Effects of sunflower seed inclusion in finishing diets for steers on performance, carcass characteristics, muscle and adipose fatty acid composition and meat quality. Can. J. Anim. Sci. 86:37-48. https:// doi.org/10.4141/A05-040.

Simopoulos, A. 2006. Evolutionary aspects of diet, the omega-6/omega-3 ratio and genetic variation: nutritional implications for chronic diseases. Biomed. Pharmacother. 60:502-507. https://doi.org/10 .1016/j.biopha.2006.07.080.

Simopoulos, A. P. 2016. An increase in the omega-6/omega-3 fatty acid ratio increases the risk for obesity. Nutrients 8:128. https://doi .org/10.3390/nu8030128.

Smith, S. B., G. W. Go, B. J. Johnson, K. Y. Chung, S. H. Choi, J. E. Sawyer, D. T. Silvey, L. A. Gilmore, G. Ghahramany, and K. H. Kim. 2012. Adipogenic gene expression and fatty acid composition in subcutaneous adipose tissue depots of Angus steers between 9 and 16 months of age. J. Anim. Sci. 90:2505-2514. https://doi.org/10.2527/ jas.2011-4602.

Tian, Y., D. Romanazzi, K. Miyashita, and M. Hosokawa. 2016. Bioconversion of docosapentaenoic acid in human cell lines, Caco-2,
HepG2, and THP-1. J. Oleo Sci. 65:1017-1022. https://doi.org/10 $.5650 /$ jos.ess 16128 .

Troy, D. J., B. K. Tiwari, and S.-T. Joo. 2016. Health implications of beef intramuscular fat consumption. Korean J. Food Sci. Anim. Resour. 36:577-582. https://doi.org/10.5851/kosfa.2016.36.5.577.

Vahmani, P., C. Mapiye, N. Prieto, D. C. Rolland, T. A. McAllister, J. L. Aalhus, and M. E. R. Dugan. 2015. The scope for manipulating the polyunsaturated fatty acid content of beef: A review. J. Anim. Sci. Biotechnol. 6:29. https://doi.org/10.1186/s40104-015-0026-z.

Vannice, G., and H. Rasmussen. 2014. Position of the Academy of Nutrition and Dietetics: Dietary fatty acids for healthy adults. J. Acad. Nutr. Diet. 114:136-153. https://doi.org/10.1016/j.jand.2013.11.001.

Waters, S. M., J. P. Kelly, P. O'Boyle, A. P. Moloney, and D. A. Kenny. 2009. Effect of level and duration of dietary n-3 polyunsaturated fatty acid supplementation on the transcriptional regulation of $\Delta 9$ desaturase in muscle of beef cattle. J. Anim. Sci. 87:244-252. https:// doi.org/10.2527/jas.2008-1005.

Wolf, C., S. E. Ulbrich, M. Kreuzer, J. Berard, and K. Giller. 2018. Differential partitioning of rumen-protected n-3 and n-6 fatty acids into muscles with different metabolism. Meat Sci. 137:106-113. https: //doi.org/10.1016/j.meatsci.2017.11.007.

Wood, J. D., and M. Enser. 2017. Chapter 20: Manipulating the fatty acid composition of meat to improve nutritional value and meat quality. Pages 501-535 in New Aspects of Meat Quality. P. P. Purslow, ed. Woodhead Publishing. https://doi.org/10.1016/B978-0-08-100593 $-4.00023-0$.

Zárate, R., N. Jaber-Vazdekis, N. Tejera, J. A. Pérez, and C. Rodríguez. 2017. Significance of long chain polyunsaturated fatty acids in human health. Clin. Transl. Med. 6:25. https://doi.org/10.1186/ s40169-017-0153-6.

\section{ORCIDS}

C. J. Byrne ๑ https://orcid.org/0000-0002-5202-216X 